\title{
Origin of Human Language in an Evolutionary Context: Evolution-Progression Model
}

\author{
Kwang Hyun Ko \\ Hanyang University Interdisciplinary Research, Seoul, South Korea \\ Email: highwaytolife2@gmail.com, kwhyunko@gmail.com
}

Received 11 February 2015; accepted 3 March 2015; published 10 March 2015

Copyright (C) 2015 by author and Scientific Research Publishing Inc.

This work is licensed under the Creative Commons Attribution International License (CC BY).

http://creativecommons.org/licenses/by/4.0/

(c) (i)

Open Access

\section{Abstract}

This article approaches what is considered to be a linguistic enigma with an interdisciplinary scientific approach. In this manuscript, the author analyzes the infant developmental stage, human anatomy, animal behavior studies, and anthropological changes. Furthermore, prominent theories in the field, such as the provisioning model, ADHD (attention deficit hyperactivity disorder) theory, and the metabolic hypothesis for human altriciality are considered in an evolutionary context to unravel the origin of language. First, two evolutionary adaptations in humans, bipedalism and delicate muscle movements, resulted in the lack of a need for "hyperfocus". Second, a relatively safe and rich environment replaced "hyperfocus" with social cohesion. Third, a burgeoning social interaction ushered in natural selection, whereby child helplessness or early parturition supported exceptional self-consciousness (intelligence). The result of concentrated selfconsciousness, which involved enlargement of the posterior parietal cortex (sense of self), prefrontal cortex (social cognition), and temporal lobe (language interpretation), was human language. Language was not a sudden revelation; instead, it was a gradual process and a built-in part of the evolutionary sequence. Last, this article implies how language might have begun in accordance with the prior multidisciplinary analysis.

\section{Keywords}

Natural Selection, Evolutionary Adaptations, Bipedalism, “Hyperfocus”, Self-Consciousness, Prefrontal Cortex

\section{Introduction}

The origin of human language has been a topic of discussion for centuries. However, there has been no general 
agreement on the origin or the age of human language. Some anthropologists, such as Campbell (2005) say "We simply do not know, and never will, how or when language began". The sheer lack of archaeological evidence makes the age of human language difficult to study. Because of this lack of direct evidence, inferences are used to address the problem of the origin of human language. The main focus of the question regarding language origin is not when, but how and why. Originally, people thought that the complexity of modern language did not appear until 100,000 years ago. Many have believed that only Homo sapiens had the capability of speaking modern language due to having a certain vocal structure. The discovery of a Neanderthal hyoid bone that is similar to that of Homo Sapiens in Kebara Cave had an impact on contemporary beliefs (Arensburg et al., 1989). The hyoid bone, which is loosely jointed to other bones, connects the tongue and the larynx, creating broader muscle movements. The hyoid itself is not a unique feature in Homo sapiens. Chimpanzees and even cats and dogs have this bone; however, a specific type of hyoid bone in combination with a descended larynx allowed human speech to appear.

Earlier, when Neanderthals had different vocal tracts from bonobos and chimps, language would have started from the babbles of a chimp. There have been many direct changes that are related to language, such as Forkhead box protein P2 and the larynx. Nonetheless, the most important part of language evolution is understanding what type of environmental pressures worked to enable these changes. The short answer is that bipedalism change and intricate hand movements made the habitat very plentiful and secure for women to give birth to helpless infants. Once a safe haven was established from predators and starvation, natural selection came into play. In an evolutionary trade-off, human infants became vulnerable from the ability to express oneself (selfconsciousness). Over time, evolution passed over individuals who had strong traits of self-consciousness, and millions of years of evolutionary pressure resulted in the helplessness of human infants.

In the following passages, I will mainly present my own hypothesis, namely, the "Evolution-Progression Model”, before examining other hypotheses in the field. This theoretical article presents human language in three phases, anthropological, animal behavior studies, and biological, and provides new light on debates that have been conducted for decades.

\section{Part I. Two Evolutionary Adaptations in Humans, Bipedalism and Delicate Muscle Movements, Resulted in a Lack of "Hyperfocus": The First Pivotal Stage of Evolution, Bipedalism}

In The Descent of Man, Darwin (1981) explains that hominids started walking on two legs to use their hands. He writes in his book, “...However, the hands and arms could hardly have become perfect enough to have manufactured weapons, or to have hurled stones and spears with a true aim, as long as they were habitually used for locomotion.” Unfortunately, a problem arises. Bipedal specializations are found in Australopithecus fossils from 4.2 - 3.9 million years ago (McHenry, 2009), while The Lower Paleolithic (Stone Age) begins 2.5 million years ago with the appearance of Homo genus/Homo habilis.

Owen Lovejoy, the director of the Matthew Ferrini Institute, came up with a modified version of Darwin's explanation. Lovejoy proposes that walking on two legs was the main adaptation for pair-bonding to succeed because carrying with two hands was an effective way to accomplish food transport. Scientists in Republic of Guinea demonstrated that chimpanzees carry twice as many nuts in bipedal walking compared with walking on four limbs (Carvalho et al., 2012).

While the presentation of food supplies increases bipedal locomotion in chimpanzees, chimps also share their food to successfully bond and to spark new relationships (Videan \& McGrew, 2002). The study by Proceedings of the Royal Society $B$ showed a mutual increase in urinary oxytocin levels in wild chimpanzees when the chimps shared food regardless of their relations (Crockford et al., 2013).

\subsection{The Second Pivotal Stage of Evolution: Delicate Muscle/Dexterous Hand Movements}

When the time was 2.5 million years ago but after bipedalism, there were evolutionary changes in anatomy that allowed delicate muscle movements to occur. Instead of the brute strength that the ape cousins have, humans developed complex muscle movements that enable tool-making (Scholz et al., 2006).

Other great apes overwhelm humans in their speed or strength, despite having undeniable similarity in their musculature. The muscle fibers of apes are longer and closer to the bones, and in addition, they are denser. Therefore, similar to how plastic bands work, thick fibers in our ape-cousins can accomplish more strength 
when using a corresponding motion (Wolchover, 2011).

Nonetheless, primates have less control over their muscles because they lack the neurological structure for restraining muscles. Excess motor neurons enable hominins to exercise smaller portions of muscles at one's will (Walker, 2009). Thus, humans can control hands individually to a higher extent. Unlike chimpanzees, humans can employ only a few muscle fibers for complex tool making and cumulatively more fibers for tasks that demand more power.

\subsection{Two Changes and Their Effects: Building Up to Human Language}

Aforementioned were two evolutionary changes in humans: bipedalism and delicate muscle movements. These changes brought three factors into play for the development of human language. The first factor is the sufficiency of nourishment, and the second factor is escape from the fear of predators. The third factor is the control of fire, which relates to the two prior points.

First, bipedalism promoted a relatively food-rich environment. Hominins began sharing food with others. Our ancestors began Bipedal-walking. Bipedalism would have consumed less energy but enabled the gathering of foods. Furthermore, the study of chimps reveals the origins of air play, showing an inclination toward an equal share in nature's closest cousins. The study published in Proceedings of the National Academy of Sciences demonstrated that chimpanzees would split the food equally with an unrelated chimp (Proctor et al., 2013). Our ancestors also possessed characters that enabled fair play and food sharing. Thus, if one failed at gathering berries and nuts, there were many others that would succeed and come back with hands full to spare food. Humans were more foragers than they were hunters; thus, using two hands for gathering was a key breakthrough against frequent starvation. Owen's prominent theory also proposed that the sexual dimorphism that proceeded with food gathering would improve the infant survival rate. Males were responsible for provisioning females while females protected their offspring.

Second, flexible muscle and versatile hand use enabled vast protection against predators. In evolution, humans developed intricate movements in return for unruly strength. Gradually, humans made technological advancements to defend against dangerous carnivores. They learned to build primitive shelters and develop stone tools. Humans also started to hunt. They were originally talented at aimed throwing and clubbing. At the beginning, humans built simple Oldowan choppers and then designed more complex bifacial hand axes in the Acheulean. Latercame the development of efficient weapons in the Middle Paleolithic, such as spears, axes, and arrows, which would grant them more protection and power.

Third, the control of fire by hominids presented a turning point in evolution. The use of fire and safe shelters near a river or cave freed our ancestors from the necessity of being vigilant at all times. The fire drove away the predators and insects and provided additional warmth to humans. Furthermore, cooking with fire allowed indigestible or toxic components of plants, such as starch, mature roots, tubers, raw cellulose, thick stems, enlarged leaves, or seeds, to be part of the hominid diet. Usually, by cooking foods, humans conserved energy on digestion, as indicated by various studies of Wrangham et al. (2010).

\subsection{Explaining the Human Language: "Evolution-Progression Model"}

Here, the origin of language appears. What would make human communication so distinctive among the communications of wild animals, apart from grammar and structure? The answer appears to be very intuitive but is indisputable.

Humans, compared to all other wild animals, do not spend most of their time communicating for actual survival. Men and women alike typically use language to engage in conversations; we talk, lecture, or listen to others in social groupings. Fortunately, people do not occupy most of their time in foraging for fruits and nuts while worrying about being killed by wild animals.

Some might argue that this circumstance is necessarily not the case for people who still live in primitive hunter communities. Surprisingly, the data presented by Sahlins (1968) and the following study of Sackett (1996) demonstrated that hunter-gatherers led ideally egalitarian lives, working far fewer hours and enjoying more leisure than typical members of industrial society; yet, subsequent research found that they still ate well and lived long lives (Guenevere \& Kaplan, 2007). Even among those people who maintain foraging lifestyles, languages are dominantly used for non-survival activities such as private conversations, lecturing juniors, or listening to elders. Language overall is a tool to direct their attention toward human communication and relationships and 
away from the diverse sounds of nature; it is indispensable for scavenging for food or watching out for natural foes.

In previous passages, I mentioned two landmarks in evolution and their impact. The essence of the "Evolution-Progression model" is that more time spent among human groups themselves instead of constantly looking out for predators or continuing the search for food dynamically drove the development of language. Now, it might seem unclear what I mean when I previously wrote that bipedalism and delicate muscle movements resulted in the lack of a need for "hyperfocus". For humans who do not "hyperfocus", there was less of a chance of surviving in unsettled and vulnerable prehistoric foraging societies. These primeval hunter-gatherer societies, remarkably, have occupied at least 90 percent of human history. What I mean by a lack of "hyperfocus" here is a loss of restlessness, attraction to novelty, extreme vigilance, a short attention span for a subject, and impulsiveness, which are alleged animalistic traits that have helped our helpless ancestors survive.

In 1995, Hartmann, whose child was diagnosed with Attention deficit disorder (ADHD), proposed that the "hyperfocus" aspect of the condition is an advantage under appropriate circumstances. Hartmann reasons that hunter-gatherers needed more hyperfocus than farmers. His theory is that gradually over time, agriculture replaced foraging in most regions. Most of the humans adapted to the farming cultures; however, people with ADHD retained some of the older characteristics from hunter-gatherer societies that preceded agriculture (Hartmann, 1995). Not-so-surprisingly, recent findings prove "The hunter vs. farmer hypothesis" to be validthe studies of isolated nomads in Kenya by Ben Campbell and other evolutionary studies show advantages of hyperfocus and impulsiveness in survival (Eisenberg et al., 2008; Callaway, 2008). Overall, the frequency of genetic variants contributing to ADHD indicates that the trait had provided a survival advantage in the past (Arcos-Burgos \& Acosta, 2007). Adding final support for the theory, many pundits, including leading neuroscientist Dr. Perry, believe that ADHD, in reality, is only a description of the symptoms rather than a genetic disorder or disease (Boffey, 2014), which is a claim that fits with the theory. So-called ADHD traits were simply factors that helped our ancestors to survive.

To clarify the difference between Hartman's proposal and the "Evolution-Progression model", there are two crucial points that must be mentioned. First, the lack of hyperfocus should not be the only dichotomy of "Farmers vs. Hunter-gatherers" that was identified in Hartman's theory. From an evolutionary viewpoint, "hyperfocus" was advantageous, conferring superb hunting skills and a prompt response to predators (Adriani et al., 2012). In this respect, humans have been hunter gatherers - throughout $90 \%$ of human history - from the beginning, before evolutionary changes, fire-making, and countless breakthroughs in stone-age societies. As humans devised better innovations and organizational structures to boost their living, the need for hyperactivity slowly diminished over a long period of time regardless of whether they were in a gathering or farming society. Diamond (1998) mentions that there was not even a straight line between the two societies. Instead, it was a slow and obscure transition, in which both farming and gathering coexisted. Moreover, farming life did not necessarily entail an improvement in sustenance. In fact, scientists have found that the first pioneering farmers were more malnourished, suffered from more illnesses and epidemics, and had a shorter life span on average than their predecessor hunter-gatherers (Guenevere \& Kaplan, 2007). Ultimately, in the far beginning of evolution, before when humans had flexible muscles and apt manual abilities, or far earlier, when they could not walk upright, the survival conditions must have been harsh for these ape-like ancestors. Hominids could not have survived without the characteristics of ADHD, such as impulsiveness or restlessness, when they were starving and completely exposed to the dangers of predators. Fortunately, as time went by, bipedalism was developed, as well as intricate muscle movements and manual abilities. Accordingly, humans made stone tools, learned to build fires and cook, and started living in secure shelters. A decreased need for hyperfocus and increasing social interactions was building the conditions for complex language.

Second, unlike Hartman's idea, it is very likely that not only ADHD but learning disabilities are consistent with this line of thought. Although not labeled as a learning disability, ADHD and disabilities such as dyslexia or dysgraphia are highly concurrent with anomalies in a similar brain region (Mayes et al., 2000). Moreover, there are many controversies that arise from over-diagnosis and the disorder itself. As support for the Evolution-Progression Model, there is a general reduction in the volume or the irregularities in the left-sided prefrontal cortex (Broca's area), posterior parietal cortex (Wernicke's area), and temporal lobe in children who have learning disabilities (Malenka et al., 2009). Why this circumstance matters is explained shortly. The prefrontal cortex orchestrates social cognition, carrying out executive function in accordance with objectives (Miller et al., 2002). Moreover, the posterior parietal cortex, the region of the parietal neocortex that is posterior to the prima- 
ry somatosensory, contains cortical fields, fostering a sense of self and planned movements with coding of the location of objects both within and out of the body frame (Krubitzer \& Disbrow, 2008; Haggard, 2009). Finally, the temporal lobe works to interpret language, emotions, and memory (Smith, 2007). If we proceed to look at the evolution of this anatomical hardware of language, the human brain has tripled over million years of evolution (Hawks, 2013); the prefrontal cortex has increased in size sixfold according to the dominant theory along with an increase in the posterior parietal cortex and temporal lobe (Jerison, 1973) (Figure 1).

Of course, remnants of the survival instinct in people are nowhere on a par with the traits of "hyperfocus" in chimpanzees. There is obviously too much difference in the brain size regions and anatomical structures overall. The former director of the Chimp Center, Sally Boysen (1999, quoted in PBS), even states, "The chimps' attention span is much, much shorter than even the most hyperactive child."

\section{Part II. Social Cohesion and Intelligence: How a Relatively Safe Environment Replaced "Hyperfocus" with Social Bonds, Leading to Natural Selection That Produced Exceptional Self-Consciousness (Intelligence)}

The previous sections above have mentioned how two evolutionary milestones in humans led to a lack of "hyperfocus" (survival traits). Social cohesion is simply stated as humans spending time among themselves. This arrangement was described before, but the association between social cohesion and self-consciousness (intelligence) must be clearly stated along with findings from animal behavior studies.

\subsection{Relationship between Animal Intelligence (Self-Consciousness) and Social Structure}

Zoologists at the University of Cambridge found that a rook, a member of the crow family, was able to drop pebbles into a jar that was partly filled with water, to drink from the jar. The canny crow chose to drop the largest pebbles first, apparently knowing that the water level would rise faster (Bird \& Emery, 2009). Some species of birds, especially corvids (in this case, the crow) accomplish such amazing feats without a cerebral cortex, the feature that all mammals have. Avian species, fortunately, do have a brain region called the basal ganglia that they share with mammals and the nidopallium, which is the basic structure involved in learning that corresponds to the human prefrontal cortex.

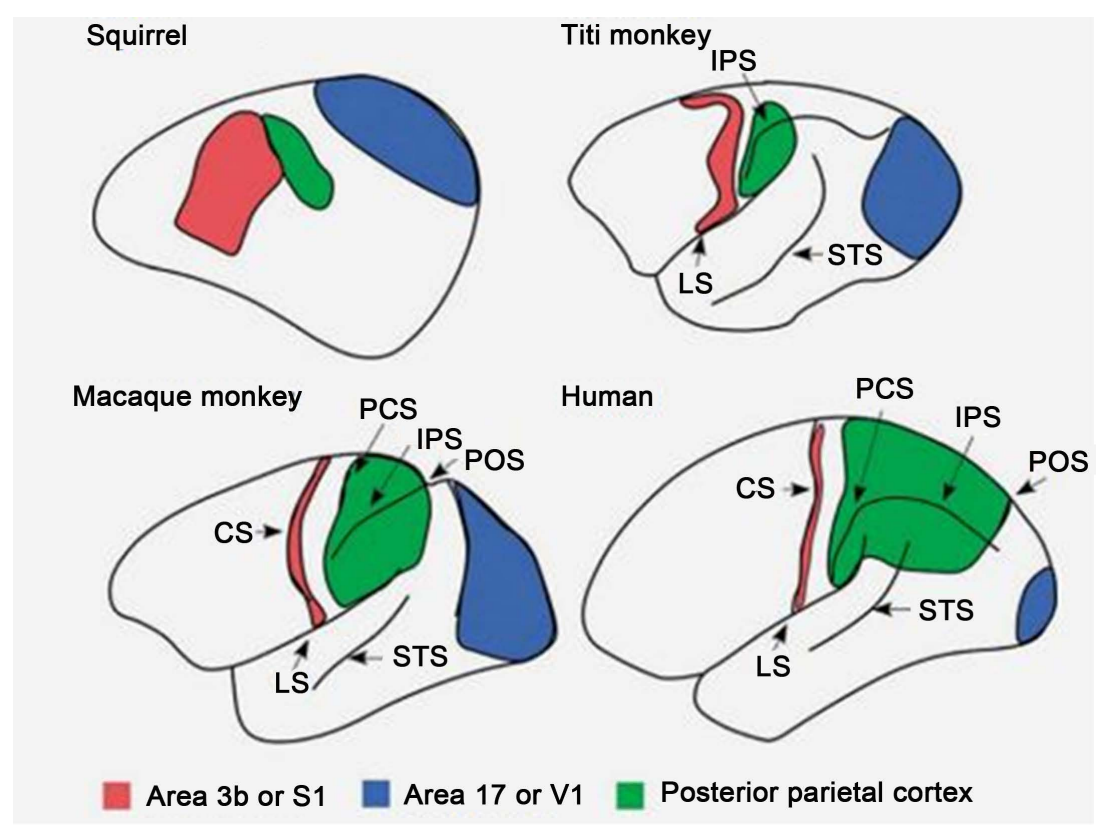

Figure 1. The brain size has increased over million years of human evolution; the prefrontal cortex has increased in size sixfold according to the dominant theory (along with the increase in the posterior parietal cortex). Krubitzer, L., and Disbrow, E. (2008) The evolution of parietal areas involved in hand use in primates. In: The Senses: A Comprehensive Reference. Volume 6, Somatosensation (Jon Kaas and Ester Gardner eds.) Elsevier, London, pp. 183-214. 
There is more contributory knowledge. Their complex social structure makes most corvids and parrots among the most intelligent and opportunistic species (Bond et al., 2003). Corvid species divide into groups to nest and protect territories. Some use teamwork for hunting, during which one bird distracts while the other catches the prey. These are social activities that require individual identification. Corvids are also known for cooperative breeding and elaborate social play, such as “follow the leader" or "king of the mountain” (Gill, 2003). Among "bird-brains", sociality has been thought to be an impetus for intelligence, for these specific species. The association between social cohesion and intelligence is not simply limited to corvids. For many other species of animals, the structure of their societies is believed to be what drives their intelligence to increase (Emery \& Clayton, 2004). Elephants, for example, are familiar species that show empathy and express concern for individuals. They mourn for a dead elephant, offer care and aid to the dying and gently scan the bones of their own kind, regardless of their relations (McComb et al., 2006).

Even though herd animals live collectively, their social structure is very limited. In a buffalo herd, Bob doesn't care who Betty is, states animal biologist Christine Drea (Kluger, 2010). Mammals such as sheep and buffalos, therefore, exhibit little cognitive ability. On the other hand, coordination and sociality are apparent in a pack of hyenas. In an animal cooperation study by Duke, the experiment would release hyenas into an enclosure where a pair of ropes hung down from an overhead platform. Only if the animals pulled the ropes all at once, the platform would spill out food. The researcher astonishingly remarks that the first pair entered into the pen and solved the problem in less than two minutes.

\subsection{Result of Increased Effort Spent on Bonding and Social Interaction: Human Language, Self-Consciousness, and High Intelligence}

Intelligence is derived from learning in social bonding and interaction, while sociality provides each unit in a group with an identity. As the height of intelligence acquired from social interaction, self-consciousness, the trait demonstrated in few of the brightest species, would be achieved. Self-consciousness is a distinguished trait that goes along with the mirror test, the general test for animal intelligence. The mirror-test, as the name suggests, is an experiment to determine whether the specific animal can recognize itself in the mirror (Gallup, 1970). Non-human species that have passed the mirror-test are the smartest of animals: primates (bonobo, chimpanzee, orangutan, gorilla), cetaceans (bottlenose dolphin, killer whale), elephants, and corvids (Eurasian magpie). The test results substantiate claims that certain species are very intelligent (Prior et al., 2008).

Among the brightest self-conscious species, such as elephants, cetaceans, and corvids, an association was shown between the number of social interactions and various learned behaviors (Poole, 1996). In the jungles of Borneo and Sumatra, Schaik (2006) conducted a specific behavior study with orangutans and chimps. The groups in which each primate had more opportunities to examine others exhibited a greater variety of learned behaviors than the groups that offered fewer chances to observe (Figure 2). This correlation was observed in both animals. The difference in learning that resulted from social interactions is attributed to "How much there is to eat", van Schaik answers (Binns, 2006). If there is a shortage of food, individuals must spend more time hunting and foraging. Therefore, there is less time for social interaction and examining others. In the "Evolution-Progression Model”, we are not talking about primates and are instead talking about humans. Humans comparatively spent interminable time among groups, observing and communicating with each other. As a consequence of the two evolutionary landmarks, humans lived in a rich and secure setting. They focused more on relations and spent time among themselves rather than what activities other animals conducted: gathering foods or watching out for predators. Increased social interaction is, in fact, what drove human intelligence (Mithen, 2006); as previously stated, a complex social structure provides a place for the individual animal, and self-recognition is born. As a result, humans are the most self-conscious of all animals, and the consequence of concentrated self-consciousness is language. Out of an extreme desire to express oneself and to communicate to others, a form of language naturally arises.

\subsection{How Language Might Have Begun}

The earliest words that humans spoke were universal sequences of the sounds /ma/ and /pa/. Ascribed to the meanings of "mother" and "father" throughout the world, "mama” and "papa" are phrases that are built from speech vocalizations and that are easiest to generate (O’neill, 2013). In addition, a series of interjections was first employed by humans. The interrogative word/syllable "Huh" is one of the most recognized syllables in many 


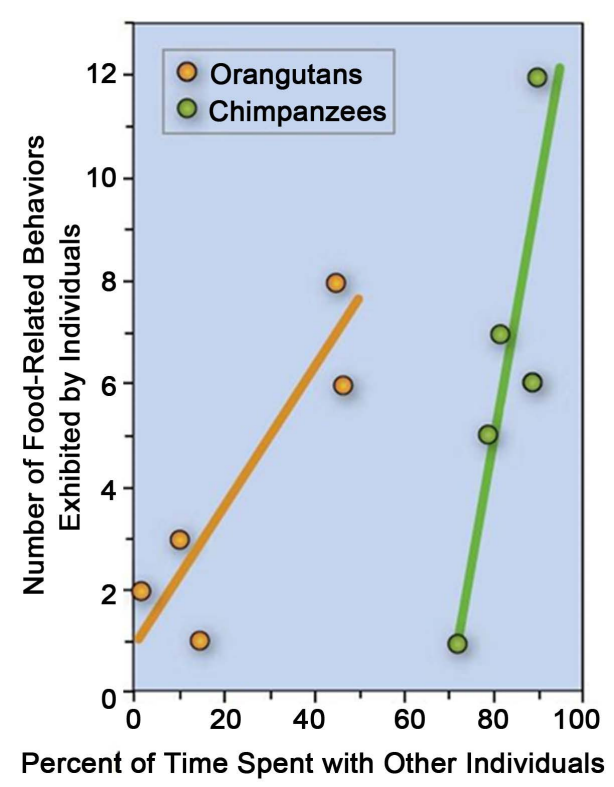

Figure 2. A social behavior study was conducted with chimps and orangutans. Groups in which each unit had a higher possibility of observing others act showed a greater variety of learned behaviors than groups that offered fewer chances. The correlation was observed in both animals. Schaik, C. (2006). Why Are Some Animals So Smart? Scientific American, 64-71.

languages of the world, covering many continents, cultures, and borders (Dingemanse et al., 2013). The use of the term "Ow" and distantly similar terms is transcontinental as well. These interjections all begin with vowel sounds. The sounds are produced with an open vocal cavity without any accumulation of air pressure, enabling effortless pronunciation for the speaker (Laver, 1994). These are among the very few universal words that humans used first. The words that followed had many variations, but there were general principles for word-making.

1) Simple, shorter sounds were designated for important words of frequent use.

2) Harsh/strong sounds (Stop, Affricate, and Fricative) were assigned for words with negative connotation

3) Many variations occurred over time

4) Be-verbs, transitive, adverbs, and syntax would come later.

The first principle is logical. Essential words that were often put into use would be kept short. For example, first person subjective pronouns are universally one or at most two syllables long, for example Wǒ in Chinese, én in Hungarian, Mimi in Swahili, and $Я$ in Russian. This principle usually works for other "necessity" words, such as mama, papa, yes, no, water, or food.

Second, hominids are assigned a negative connotation for certain sounds because they were an indication of danger. Studies have shown that people instinctively perceived danger from sharp shapes that were reminders of stings, claws, and the fangs of insects and predators (Bar \& Neta, 2006). More interestingly, Köhler (1929) indicated that there was a strong preference to match the jagged shape with "takete" and the roundish shape with "baluba". The study was repeated with different words, "kiki” and "bouba” ("maluma” in the 1947 version), and conclusively led to a correlation between certain sounds and shapes. Certain sounds, such as [k], did requirea relatively stiffer, angular mouth form and a more taut, clenched jaw than other sounds. The sounds gave a "sharp” and "jagged" impression. Thus, humans subconsciously prescribed negative overtones to these vocalizations. Generally speaking, the "harsh" sounding words carry a negative meaning. For example, ancient Greek words such as "kakos (evil)" or "kaos (chaos)" are made from a taut mouth shape and closed jaws, compared to nonnegative words such as "hydro (water)" and "helios (sun)".

The third principle is that many variations occur over time. Pagel (2009) compares language evolution to a massive game of "Chinese whispers", where the last person in the line ends up speaking gibberish. Languages change over time because of speakers' desires to pronounce words with ease. In old English, for example, the words for "bird" and "horse" were "brid" and "hros", which are slightly more difficult to pronounce. The alteration of sounds would continue further with the advent of writing. 
Be-verbs, transitive, adverbs, and syntax would come later, as the final principle that our hairy predecessors would have first spoken in baby talk. Unconnected talk without be-verbs or adverbs would have served its purpose in the beginning. Early ape-like hominids without fire and stone tools had difficulty surviving in unprotected environments. It was literally "To be, or not to be”. Similar to other animals, humans simply remained alive by foraging and avoiding predators. There were not complex situations, where "I would prefer going", "I go", or even "go" would make a difference. Moreover, before the primitive language and the advent of writing, typical grammar such as parallelism, run-ons, or fragments would not even matter. As complex organizations arose in more developed societies, grammar structures occurred naturally from a need to specify one's exact purpose. The human brain size, consciousness and intelligence grew as hominids started living in more settled societies. A handful of nouns were assigned, with a few adjectives and verbs to express and recognize them. Individuals also agreed on words to express or label themselves and others. Later would come words such as conjunctions, adverbs, and be-verbs.

Eventually, our ancestors built what we would call human language. Primitive language before proto-writing, however, was not anywhere close to modern language. Oral languages are extremely short, redundant, and colloquial. The number of words that are required for speaking is very small compared to the 20,000 words or more that people would need to write a long essay or to read good literature. For example, the oral language of Piraha has approximately a few hundreds words or less (Everett, 1986).

The process of language creation is described shortly because the question that this article adresses is how basic primitive language began; the question is not how complex languages such as English, which has diverse syntax and two million words, developed over time.

\section{Part III. The Natural Selection Whereby Child Helplessness or Early Parturition Produced Exceptional Self-Consciousness (Language)}

Previously, I stated two pivotal evolutionary changes that led to the loss of "hyperfocus" and explained in Part II how a relatively safe environment replaced "hyperfocus" with social bonds, leading natural selection to favor exceptional self-consciousness (intelligence). In this section, I will explain the biological process behind natural selection, relating anatomy and evolution to language: How infant helplessness produced concentrated selfconsciousness (language):

Last, as a part of the evolutionary sequence, humans lost the traits of hyperfocus over time while they obtained the ability to learn language. The evidence is supported by a long development stage of humans. The human infant is more helpless than those of all other primates. Moreover, human babies fall behind infants from other species at every stage of inchoate development. "One of the things that set modern humans apart from the living great apes is our long period of growth and development”, Christopher Dean of University College, London explains (Dean et al., 2001). Newborns of some other species depend on birthmothers, but a human infant takes months to support itself by standing on its own two (or four) feet and years to master even the simplest tasks, such as walking properly, preparing a meal, or sleeping alone. A human child remains completely dependent on parents to care for their every need.

Why would mothers give birth to helpless babies? The scientific reason behind helpless infants is very simple. An idea was originally made by Peter T. Ellison for the explanation of infant helplessness. Study co-author Duns worth and her team support the theory, which is known as the metabolic crossover hypothesis. They claim that "Energetic constraints of both mother and fetus are the primary determinants of gestation length and fetal growth in humans and across mammals" (Dunsworth et al., 2012). Near the end of a pregnancy, the maturation of the human fetus places a heavy burden on the mother, and metabolic demands reach the mother's limitations in meeting both the baby's energy requirements and her own. In other words, the mother must perform labor due to the large amount of energy that the baby consumes. Extensive studies in an array of non-human mammals also indicate a limit in the development of a fetus due to how much energy-draining it can do and how large it can grow during the gestation period, while recent analysis refutes the traditional obstetrical dilemma hypothesis (Wong, 2012).

\subsection{Energy and Early Brain Development}

The question arises, why would human babies be so energy-consuming? The energy-draining perspective of a fetus relates substantially to brain development. Most of the brain development takes place within the first three 
years of human life. At birth, a human baby’s brain starts at 369 cc, and it rapidly grows to approximately 961 cc during the first year of life (Peters, 2006). Although the human brain represents only $2 \%$ of the body weight, the brain consumes a large amount of energy in proportion to its volume. The brain demands $15 \%$ of the cardiac output, $20 \%$ of the total body oxygen consumption, and $25 \%$ of the total body glucose utilization (Munck \& Lassen, 1957). Human babies are defenseless during their early years as their brains make key neural connections - a process known as pruning.

Nevertheless, we must attempt to answer what could be the evolutionary reason? The final question yet remains unanswered: the reason why babies have this early development stage that would have made them vulnerable to predators and harsh survival settings.

The following is our proposed response: The only answer is that bipedalism changes and intricate hand movements made the habitat to be a very rich and safe setting for women to give birth to helpless infants. The two evolutionary stages mentioned earlier shaped the environment around them. Hominids carried foods with two hands, gained control of fire, and developed stone tools. In an evolutionary trade-off, human infants became vulnerable because of their ability to express themselves or self-consciousness. Over time, evolution passed along individuals who had strong traits of self-consciousness, and millions of years of evolutionary pressure resulted in the helplessness of human infants.

\subsection{Brain and Language: Connection to Infant Helplessness or Early Parturition}

The research by Gogtay (2004) reveals active development in posterior parietal cortex (sense of self), prefrontal cortex (social cognition), and temporal lobe (language interpretation) in the early years (Figure 3). Such anatomical evidence verifies studies of how connections for language and cognition are remarkably responsive in toddlers (Nelson, 2000). In addition, early regional development matches evolutionary changes in the brain. The human brain has tripled over a million years of evolution (Hawks, 2013); the prefrontal cortex has substantially increased along with an increase in the posterior parietal cortex and temporal lobe (Jerison, 1973). In other words, the increase in the brain's size was implemented through a long infantile development period in humans.

In part II, the article mentions the earliest words that humans spoke. "Mama" and "papa" are phrases that are built from the speech vocalizations that are the easiest to produce, and a series of simple interjections such as "huh?" and "Ow" were generated without any build-up of air pressure. This pattern relates to the biological changes that I have mentioned. These specific phrases were easily spoken by infants to call out to their parents,

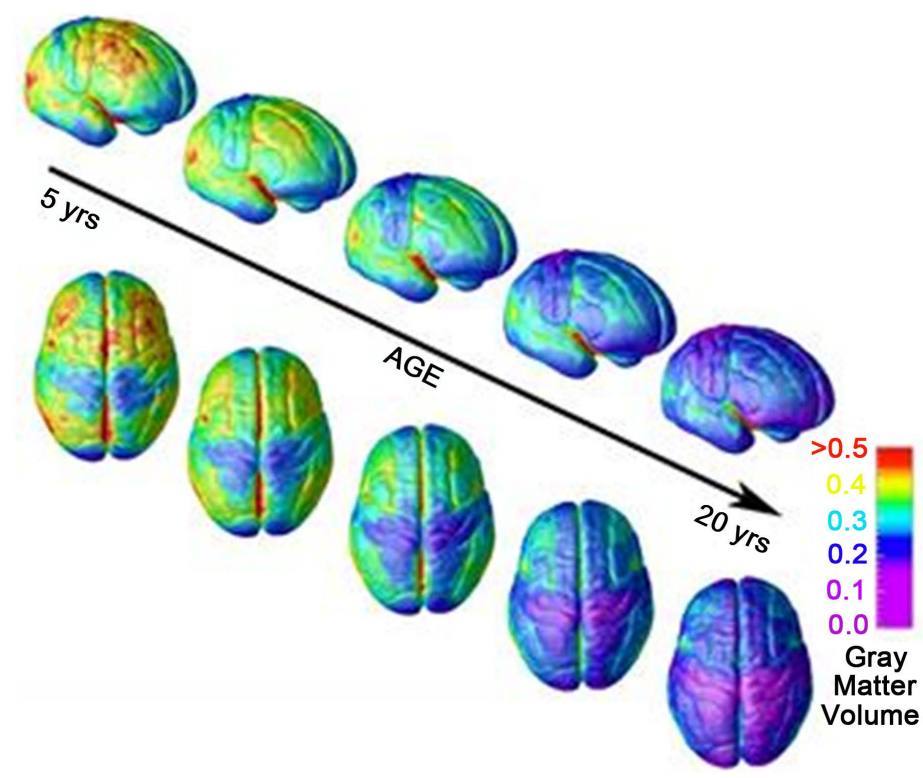

Figure 3. Active development of posterior parietal cortex (sense of self), prefrontal cortex (social cognition), and temporal lobe (language interpretation) in early years. Gogtay, N. (2004). From the Cover: Dynamic Mapping Of Human Cortical Development During Childhood Through Early Adulthood. Proceedings of the National Academy of Sciences, 8174-8179. 
to satisfy their curiosity, or to cry out for pain. Because of how evolution works, the earliest words to be spoken by humans apparently came out of babies' mouths (language mutation in a newborn). At one point, an infant with a different larynx instinctively prescribed simple sound sets for mother, father, curiosity, and pain. In fact, toddlers who expressed their specific needs would have elicited more attention from their parents and group members. Because these toddlers were able to express their exact needs and draw more attention from adults, the babies were more likely to survive compared with other infants who could not speak at all.

How were parents able to adhere to the needs of the talking babies? Even if parents themselves could not vocalize human sounds, they would have eventually known the meanings of sundry babbles from numerous practices and from their natural instinct, similar to how domesticated dogs and non-wild animals interpret human phrases. The evolution of language would subsequently continue, as grown-up hominids with vocal capabilities agreed upon various sounds to designate certain meanings.

With respect to further biological implications in human language, the posterior parietal cortex (the region of parietal neocortex posterior to the primary somatosensory) contains cortical fields, handling "the sense of self" and planned movements with the coding of locations of objects both within and out of the body frame (Krubitzer \& Disbrow, 2008). Increasing the "sense of will" in the posterior parietal lobe naturally embedded meaning and intention in language while creating syntax to aid in representations. The principal activity of the prefrontal cortex, on the other hand, is considered to be the management of social cognition, carrying out executive functions in accordance with goals (Miller et al., 2002). Social cognition, therefore, bestowed humans with talent for analyzing social context and situations. The temporal lobe works to interpret language, emotions, and memory (Smith, 2007). The temporal lobe, last, serves to store sounds and meanings of language for possible interpretation.

\subsection{Addition to the Conclusion: Enlargement of Brain Regions-Sulcus Lunatus}

In series short-term memory tasks such as memorizing the sequential order of numbers and recalling them, the performance of young chimps exceeded those of human adults (Matsuzawa et al., 2007). Chimps are apparently superior to humans at accomplishing instantaneous memorization. Matsuzawa suggests that there could be an evolutionary tradeoff between the eidetic/photographic memory shown in these chimps and the higher cognitive abilities of humans, such as an advanced capability for complex language (Choi, 2007). In this regard, the simian sulcus, which is also known as the sulcus lunatus, is an anatomical fissure between the temporal and occipital lobes that is found in primates (Allen et al., 2006). Interestingly, the lunate sulcus lies at the back of human brains while the brain fissure of chimpanzees is located further front. In chimps, the fissure would allow more free connections between the two lobes, granting the storage of visual memory. The specific location of the fissure in humans, however, would limit the connections between the temporal and occipital lobes. In turn, the temporal lobe in humans would form more connections to the posterior parietal lobe and prefrontal cortex.

Many animals besides chimps depend on eidetic memories for survival. Our ancestors, however, did not require photographic memories due to having a satisfactory survival setting built by previous evolutionary stages. Humans did not need to pinpoint the exact location of predators or food because they lived in a rich, protected environment.

\section{Conclusions}

Consequently, the "Evolution-Progression Model" describes how humans could have obtained language using a multidisciplinary approach. In Sentences of Peter Lombard, Ockham, a Franciscan friar and theologian, mentions the problem-solving method, Occam's razor. The principle states that among competing hypotheses, the hypothesis with the fewest assumptions should be selected. The "Evolution-Progression Model" is Occam's razor. Unlike any of the other theories that explain the origin of language, this model does not make special assumptions. It literally retraces evolutionary time to explain how primitive human language began. The hypothesis is concise, logical, and relevant.

\subsection{Fire and Brain Increase}

The brain size in hominids increased steadily overtime, but from 1.6 million to 1.8 million years ago, the trend of this brain increase sharpened. This steeper increase in brain size is explained by the early control of fire in 
Homo erectus. Fire makes foods easier to digest, and thus, humans would have had more extra calories. "The energetic consequences of eating cooked meat are very high,” says Wrangham. The study by Carmody et al. (2011) found that mice given cooked meat gained $29 \%$ more weight than the mice that were fed raw meat, over 5 weeks. Mice that ate raw calories weighed less, although they consumed more meat (Gibbons, 2007).

\subsection{Questions Facing Science}

Science Magazine’s special 125th anniversary issue listed "25 big questions facing science over the next quarter-century". One of the questions is "What Is the Biological Basis of Consciousness?" (Miller, 2005). Narrowing down this ultimate question, the writer mentions specific challenges: the biological basis of consciousness and the evolutionary pressure that led to its development.

The explanation of human consciousness is simple. What goes inside of our mind is a chaotic mixture of images, senses, and verbal thoughts. Sensual and visual memories are largely observed in studies of non-human species. What makes the difference is our verbal thoughts formed by human language. Scott (2013) indicates that the inner voice in our minds is actually a prediction of our own sounds. The auditory memory of external sound stored in the brain allows humans to "hear" thoughts. In this case, auditory memories are verbal communication sounds. The evolution of human thoughts or consciousness, therefore, comes down to how humans began speaking language.

\subsection{Re-Cap of Summary}

As a final remark, Kanzi, the male bonobo, can communicate using lexigrams (specially designed graphic symbols) but cannot pronounce in a way that is coherent to most humans. At one point, it was observed that every time that Kanzi communicated, he also produced some vocalization. Surprisingly, Kanzi was actually articulating the sound counterpart of the symbols that he was expressing. The male bonobo was saying the words, although in a very high tone and with distortions.

Originally, people thought that the intricacy of modern language did not appear until 100,000 years ago. Many have believed that only Homo sapiens had the capability to speak modern language due to having a specific vocal structure. The discovery of a Neanderthal hyoid bone that is similar to that of Homo Sapiens in Kebara Cave had an impact on the contemporary belief (Arensburg et al., 1989). The hyoid bone, which is loosely jointed to other bones, links the tongue and the larynx, producing broader muscle movements. The hyoid itself is not a distinctive feature in Homo sapiens. Gorillas and even cats and dogs have this bone; however, a specific variety of hyoid bone in unison with a descended larynx allowed human speech. It remains controversial whether the discovered hyoid bone indicates the larynx's lowered position or not.

Before the time that Neanderthals had different vocal tracts from Bonobos and chimps, language would have started from the babbles of a chimp. There were many direct changes that were related to language, such as Forkhead box protein P2 and the larynx; however, the most important part of language evolution is understanding what types of environmental pressures worked to enable these changes.

Two evolutionary changes in humans, bipedalism and delicate muscle movements, resulted in the lack of a need for "hyperfocus". Hyperfocus was replaced by social bonding. Growing social interaction and a safe environment led the progression in which infant helplessness or early parturition developed self-consciousness. The result of exceptional self-consciousness was the enlargement of posterior parietal cortex (sense of self), prefrontal cortex (social cognition), and temporal lobe (language interpretation). Language was not a sudden revelation but was a gradual process instead, a built-in part of the evolutionary sequence.

First, we had the bipedalism change; the aforementioned studies demonstrated how bipedalism enhanced food transport. Lovejoy also presents the Provisioning model, which attaches the evolution of bipedalism to monogamy. Lovejoy theorizes that, in addition to the efficient transfer of sustenance, sexual dimorphism in food gathering would improve the infant survival rate. Males were responsible for provisioning females and their offspring. Females would mate exclusively with that male, and males would no longer need to fight with each other over the females. Therefore, males' jagged, blade-like canine teeth diminished over time. This change is endorsed by the downsizing of the male canine teeth—prevalent in the ape world—in early hominids such as Ardipithecus ramidus and Sahelanthropus tchadensis (Suwa et al., 2009; Brunet et al., 2002). Finally, bipedalism itself proved to be energy-efficient. Scientists who examined chimpanzees on treadmills discovered that the chimps demanded 75 percent more calories while walking than bipedal humans, which indicates proof that the two-legged walk has advantages (Sockol et al., 2007). 
A second factor is escape from fear. Humans developed complex hand movements in return for wild strength. Gradually, humans made technological innovations to guard against predators. They were good at aimed throwing and clubbing. Moreover, they learned to build primitive shelters and develop basic weapons. The use of fire and comparatively secure shelters near the river or cave freed our ancestors from the necessity of being watchful at all times. Once a safe haven was established from predators and starvation, it was again natural selection that came into play.

Third, the control of fire by hominids presented a turning point in evolution. The use of fire and safe shelters near the river or cave freed our ancestors from the necessity of being vigilant at all times. The fire drove away predators and insects and provided additional warmth to humans. Furthermore, cooking with fire enabled inedible components of plants, such as tubers, raw cellulose, mature stems, thick leaves, or seeds, to be part of the hominin diet. By cooking foods, humans preserved energy on digestion, as indicated by various studies of Wrangham et al. (2010). This outcome accounts for the steeper increase in brain size 1.6 million to 1.8 million years ago. Herculano-Houzel and Karina (2012) calculated the number of hours per day that various primates take to eat the calories of raw food that are necessary to fuel their brains. They found that it would take 9.3 hours for humans, while 7.8 hours and 7.3 hours would be required for orangutans and chimpanzees. The varied numbers showed an upper-limit on the energy that is achieved from a raw uncooked diet in primates.

As previously stated, some species are considered to be more intelligent than others because of their complex social structure, whereby each individual becomes sufficiently conscious of oneself to be able to pass the mirrortest. African grey parrots are the most gregarious birds, having a long life span and strong social bonds. They hunt or communicate in large groups. Hominids' and dolphins' complex social life requires communication skills, which in turn requires comparatively large brain size for animals of similar size and for intricate echolocation (in dolphins).

Some have insisted on the Machiavellian intelligence hypothesis to explain the correlation between social life and intelligence. This approach argues that the smartest creatures would make the most self-protective choices and proliferate to pass their heredity to the next generation (Schaik, 2006). However, this scenario is most likely not the case for the following simple reason: most animals are not sufficiently intelligent to make self-conscious decisions. Most do not possess self-awareness and cannot recognize themselves. They are not fully conscious of their actions. Instead, it is the other way around: social grouping gives consciousness that would the drive Machiavellian intelligence.

\section{Discussion: Clearing up the Difference between "Self-Consciousness" and "Consciousness": 25 Questions in Science}

The meaning of "Self-consciousness" as used in previous passages is different from that of "consciousness". Self-consciousness is highly exclusive to intelligent species, but consciousness is not limited to certain species. These two terms are sometimes used interchangeably. In this specific case, "consciousness" is a broader term for general cognitive processing, while "self-consciousness" is defined as having a sense of ego. At the zenith of self-consciousness, we have language. What I attempted to say in the last paragraph is the following: we have language running in our thought processes, but animals do not.

\section{1. "Self-Consciousness" and "Consciousness"}

Surprisingly, when chimps see a mirror, they can recognize themselves and know what they are, in fact, doing. This phenomenon explains how some of the distinguished primates can grasp the concept of language. Unfortunately, cows, cats, pigs, or goats do not contain any real sense of ego and are not capable of self-recognition (Nosowitz, 2013); however, these non-intelligent species are still "conscious" of their surroundings and can learn from basic conditioning. When I say "consciousness" in the "25 Questions in Science", I mean the basic thought process that is shown in many, including non-intelligent, species. Cats and goats "think", but "think" only instinctively. There are no words to their thoughts. Their thoughts are a chaotic amalgam of sounds, senses, and images that are necessary for survival.

\subsection{Blindness and Self-Consciousness}

The mirror test is one way to test for self-consciousness, but blind people would not be qualified for this test. Blind people are, no doubt, self-conscious, despite the fact that they cannot see. This arrangement occurs be- 
cause the brain (Wernicke's area) is in control of "self-consciousness". I also stated how language itself is mainly the work of the brain. Visual, auditory, and vocal systems are important but auxiliary in regard to their role in learning a language.

I did not mention blind people in part II for a simple reason: it is difficult to consider people who have congenital blindness in evolution because they would have suffered early deaths in prehistoric times. Additionally, even a few decades ago, most people who were considered to be "Blind" ended up in wretched, ghastly conditions, unless they were cared for by families or friends (Shattuck, 1980).

\section{Examining Other Theories}

\subsection{Grammatical Theory-Language-Too Complex?}

Chomsky and discontinuity theorists hold that language is the result of an abrupt mutation in the human species, refusing the view that a "language organ" could have evolved from preexisting components of animals. These theorists claim that humans are born with an innate "organ" that enables grammar and syntax. Unfortunately, various animal behavior studies have proved otherwise.

Washoe, a female chimpanzee, was the first to learn American Sign Language to a limited degree as part of research on animal language acquisition. Washoe learned approximately 350 words of ASL (Johnson, 1993). Another distinguished primate is Kanzi, who was trained by Dr. Savage-Rumbaugh. Kanzi is a bonobo who knows complex questions, 3000 words, lexigrams, and syntax. He once tried to eat kale and named it "slow lettuce” because it takes more time to chew than regular lettuce (Raffaele, 2014).

Alex, an African grey parrot was the subject of a thirty-year experiment by animal psychologist Irene Pepperberg. He called an apple a "banerry", which Pepperberg thought to be a combination of "banana" and "cherry," two fruits that he understood. Alex understood the communication process and often combined words that he already knew to form new words and sentences, demonstrating that he had known syntax used in language (Wise, 2002).

Scientists trained primates and birds to talk, while people with inborn defects or permanent brain damage are unable to speak. This finding suggests the following question: why are we arguing about an innate language organ?

Continuity theorists depict human languages to be "so complex" to have simply emerged from animalistic communication or cognition. I guess there is still an unscientific obsession to believe that there are parts of evolution that made humans be sacrosanct. This major confusion about human language being "so complex" stems from two false premises: assuming that language did not undergo a large amount of modification and assuming that all languages are similar to English.

Change in language. In contrast to what many theorists presume, languages have changed over time. 10,000 years ago or even before, language use was solely oral because writing was nonexistent on Earth. Unfortunately, oral languages compared to written languages have shorter sentences and a smaller variety of repeated words while containing extremely exaggerative, colloquial, and vague nouns; in addition, they have overstated interjections (McCroskey et al., 2003). According to Arguelles, an estimated 250 words are needed for speaking in everyday life, while the comprehension of 20,000 words is mandatory for people to recognize meanings, to be able to read, understand, and enjoy a work of literature, a novel, or a news article (Bond, 2013). Without a system of writing, human language was not as complex as it is today. If we were to consider early hominids who did not even have proto-writing/symbols, the antecedents of alphabets, human language would have been extremely basic and instinctive.

English is not similar to other languages. Second, English, unfortunately, is not very representative of other languages. The English language is likely to contain the largest number of words of all languages. Estimates for the number of words range from one to two million, according to the Oxford English Dictionary. Some languages, such as Pitjantjatjara, contain about 10,000 words, a lot of which were incorporated from Western Languages. Others, such as the Piraha language, do not show clear signs of syntax (Banting, 2003; Everett, 2009). Apparently, the extent of complexity for each language does differ depending on the culture. Natives in non-industrialized regions still use very few words in their language. Many nomadic hunter-gatherer populations in continents failed or did not find the need to develop a written language. Diamond (1998) explained the cultural imbalance such as the advent of writing in Eurasia, examining environmental and geographical factors. Regardless of the reason, the conclusion is simple: not every language is as intricate as English. 
Is the language faculty non-linguistic? A language module, a concept first proposed by Noam Chomsky in the 1960s (named LAD), is a hypothesized structure in the human brain that contains an innate capacity for language. Psycholinguists such as Pinker and Fodor claim as well an instinctive predisposition and inborn ability that enables toddlers to acquire language. However, no available evidence confirms that one anatomical area is solely devoted to the process of language (Wada \& Rasmussen, 1960).

Yes, language faculty is non-linguistic. The allegedly complex syntax and grammar in language is not, in anyway, encoded anatomically. "Language acquisition” occurs through a biological process. The complexity of human language arises naturally and anatomically from concentrated self-consciousness and social cognition in humans.

Moreover, language is mainly the work of the brain. The visual, auditory, and vocal systems are important, but they are auxiliary with respect to their role in language. The innovative systems of sign language and English Braillehave helped deaf and blind people to demonstrate their aptitude in language. With modern social service and educational care, people with congenital deafness, blindness, or dumbness scan now reach their full capacity for language. On the other hand, people who have permanent injuries in Broca's area (Prefrontal Cortex) and Wernicke's area (posterior parietal cortex) suffer from language comprehension or speaking impairments. In most cases, the damage to language comprehension and speaking is unrecoverable. Consequently, the human brain itself alone holds an innate capacity for language, even regardless of the larynx and the hyoid bone.

Biologically speaking, a period of infant helplessness and early parturition help to develop the exceptional capability of self-consciousness (intelligence). Because of this exceptionally extensive early developmental stage, humans, compared to other primates, have especially large posterior parietal cortex (sense of self), prefrontal cortex (social cognition), and temporal lobes (language interpretation). As a result of natural selection from a special environment that was gradually set off by two landmarks in evolution, humans, unlike other primates, have the brain structure that is apropos for language. A further implication for human language is that the posterior parietal cortex contains cortical fields that handle "the sense of self” (Krubitzer \& Disbrow, 2008). Increasing the "sense of will" in the posterior parietal lobe naturally embedded meanings and intentions into language while creating syntax to represent relations with one another. The principal activity of the prefrontal cortex, on the other hand, is considered to be the management of social cognition, carrying out executive function in accordance with goals (Miller et al., 2002). Social cognition, therefore, bestowed humans with talent for analyzing social context and situations. The temporal lobe works to interpret language, emotions, and memory (Smith, 2007). The temporal lobe, last, served to store the sounds and meanings of language for possible interpretation.

However, does it mean that language is not a cultural system that is learned through social interactions? No, this question is very tricky. Increased social interaction in humans was originally the impetus behind the evolution, rendering humans more and more conscious. Nonetheless, compared to any other species, human babies are extremely vulnerable during their early years. It is not feasible for babies to survive on their own without human care. Human infants have trouble moving around or even sleeping on their own; thus, they cannot possibly live in the wild by foraging. In addition, wild animals are predators and not protectors of human infants, unlike the mythological babysitters of the Romulus Brothers or Atlanta. Every baby who makes it into adulthood, assuming that they have no genetic disease, is nurtured by human adults such as their parents or guardians. In any scenario, babies who "survive" learn language. This process does not have to involve quality parenting. Even if there are poor caregivers nurturing them, babies will pick up any words or sentences that are spoken by their caregivers and eventually succeed at understanding the concept of human language. Consequently, the question of whether language is something that is learned culturally becomes difficult to answer.

There are, however, very rare historical accounts in which babies did make it into adulthood without parental care, such as Victor of Aveyron or the recently found Vietnamese "jungle boy". The first example, Victor of Aveyron (c. 1788-1828), was a French feral child who passed the majority of his childhood abandoned in the forests (Smith, 1984). Having no prior experience with human society, Victor stayed mute. This wild boy did not learn language even when Victor had proven that he was neither deaf nor mute (Shattuck, 1980).

In the recent case in Vietnam, a Father and son, emaciated and disarranged, were found in a forest of Quang Ngai province after 40 years in isolation under the hard conditions of the jungle (BBC, 2013). Local media reports that a bomb explosion in his home killed his wife and two children during the Vietnam War. Ho Van Thanh fled during the war into the woods with his then-infant son. When found, they both could not speak. After 40 years of isolation under the hard conditions of the jungle, the father could communicate very little in the eth- 
nic Cor language; Ho Van Lang, the 42-year-old son, only knew a few words.

In addition to the particular vulnerability of infants, their brains make key neural connections in the first few years-a process known as pruning (Figure 4). Early learning-specific experiences of sensation, language, and cognition-shape a child's brain to develop a strong foundation for adult intelligence from the moment the children are born. At this stage, caring and social interaction with the child is necessary if not obligatory. What is the conclusion? Automatic 3-D food printers would never be a replacement for human care.

\subsection{Gestural Theory}

This school of thought sees human language as having developed from gestures that are used for iconic communication. Observing partially genetic gestures in animals, the supporters of the gestural theory, such as Tomasello, posit that human language originated from the manual gestures of primates. For example, gorillas beat their chests, or chimps might pounce. Nevertheless, many doubts remain for this theory.

Main communication observed in animal vocalizations. To begin with, primates and many animals mainly use vocalization in communication. In gorillas, twenty-five distinct vocalizations are dominantly used for group communication. While gorillas travel, sounds recognized as grunts and barks are used to indicate the locations of individual members (Harcourt et al., 1993). Common chimpanzees as well largely use distance calls to draw attention, signal alarm, and indicate food sources or other community members (Goodall, 1986). Bonobos also communicate primarily through vocalizations. Because humans' closest cousins chiefly engage in vocal communication, there is no reason to believe that language arose from gestures. Not only primates but also herd animals, reptiles, and cetaceans use mostly sound for communication. Herd animals make different moo sounds; reptiles such as crocodiles generate varied cries, and cetaceans produce diverse clicks (Mathevon et al., 2013). Consequently, Darwin's evolution cannot explain how human communication arose from gestures.

Gestures-supplementary communication in animals. Gestural theorists yet claim that gestures are precursors of human language, pointing to specific communicative gestures in primates. Primates, however, have very different muscular structures and motor neurons, and thus, they are anatomically capable of creating only vague gestures. Great apes engage in vocal communication, hooting and screeching in various ways. Other relatively bright species also use "gestures", but only as supplementary means of communication. Dolphins, for example, mostly use echolocation and vocalization, such as whistles and clicks, to communicate, but they also use non

\section{Center on the Developing Child}

HARVARD UNIVERSITY

\section{Human Brain Development \\ Synapse Formation Dependent on Early Experiences \\ (700 per second in the early years)}

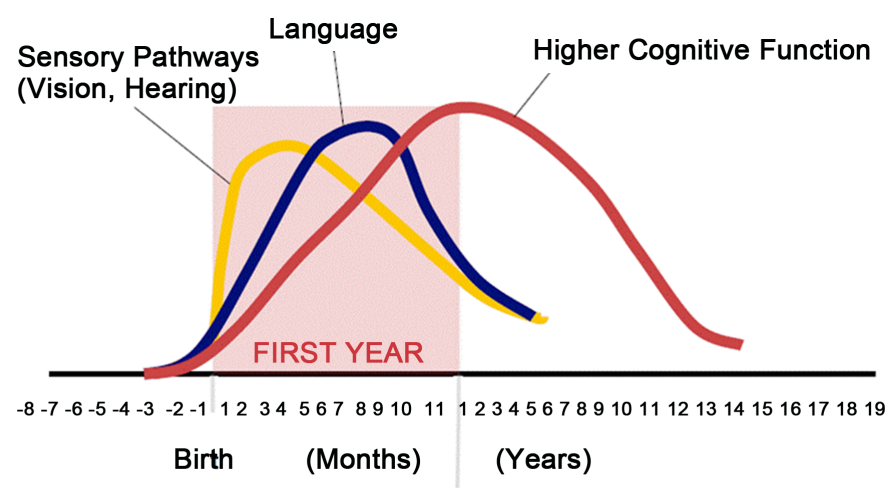

Source: C. Nelson (2000)

Figure 4. This figure shows that the connections for language and cognition are remarkably responsive in toddlers, although this development stage occurs over a longer time period. Nelson, C.A. (2000). The neurobiological bases of early intervention. In J. P. Shonkoff, \& S. J. Meisels (Eds.), Handbook of Early Childhood Intervention, Second Edition (pp. 204-227). Cambridge, MA: Cambridge University Press. 
verbal communication by means of moving tails, flapping fins, and touching one another (Dudzinski \& Frohoff, 2008). Ravens, the smartest of the bird species, use their "hands" in addition to various cries and singsongs in communication. Crows employ their wings and bills to engage in play, offer, point, and present items (Pika \& Bugnyar, 2011). These nonverbal, "gestural” cues are used in every other animal, such as gibbons, hyenas, and great apes, as a subsidiary tool for communication. The gestures that are used by primates do not show that human language arose from body language. The most intelligent species display "gestural communication" but chiefly use vocal communication. Therefore, gestures in primates or chimps cannot substantiate anything about the gestural theory. It is more logical to believe that the gestures of common chimpanzee-human ancestors evolved into the gestures of humans, while various calls evolved into oral language.

Gestures observed in our closest relatives. Proponents of the theory might again note how wild chimpanzees are especially known for using more gestures than other animals in communication. What is more important to know is the fact that gestural communication in chimps is the simple result of increased bipedalism. In other words, chimps use gestures a large amount only because they can use them. In terms of genetics and anatomy, chimps are more closely related to humans than they are to the remaining great apes (Wildman, 2003). For example, orangutans have significant adaptations for arboreal locomotion because orangutans spend the largest amount of time in trees of all the great apes (Schwartz, 1988). In other words, orangutans are not fit for bipedal motion on terrain. Bipedalism in gorillas is also rarely documented because gorillas are an inactive ape species that primarily sits and digests leaves (Hughes, 2001). The common chimpanzee, however, can walk upright for short distances, in contrast to the quadrupedal ape, orangutan or, largely "knuckle walker", gorilla. Chimps use hands frequently because they are more bipedal than the other great apes. Their gestures are not obviously precedents of human language.

It appears that primates depend substantially on gestural communication because apes do not have the capacity for human language. The situation was similar for hominins who preceded evolutionary changes. Before humans spoke complex language, hominins probably relied more on gestural communication than they do now. Nevertheless, this scenario does not mean that human language came from gestures. Human language arose naturally from the evolution of increasing sociality, hyoid bone, and brain development. Eventually, the concreteness and specificity of human language that arose from vocal language replaced the vagueness of the body gestures that were often used in communication.

\section{Acknowledgements}

Thanks to Stuart A. Newman and Francisco Todd for encouragement, and special thanks to my family for their support and care throughout the process.

\section{References}

Adriani, W. (2012). Special Focus Box: Evolutionary Perspectives on ADHD. In C. Stanford, \& R. Tannock (Eds.), Behavioral Neuroscience of Attention Deficit Hyperactivity Disorder and Its Treatment. Heidelberg: Springer-Verlag Berlin Heidelberg.

Allen, J. S., Bruss, J., \& Damasio, H. (2006). Looking for the Lunate Sulcus: A Magnetic Resonance Imaging Study in Modern Humans. The Anatomical Record Part A: Discoveries in Molecular, Cellular, and Evolutionary Biology, 288A, 867-876. http://dx.doi.org/10.1002/ar.a.20362

Arcos-Burgos, M., \& Acosta, M. T. (2007). Tuning Major Gene Variants Conditioning Human Behavior: The Anachronism of ADHD. Current Opinion in Genetics \& Development, 17, 234-238. http://dx.doi.org/10.1016/j.gde.2007.04.011

Arensburg, B., Tillier, A., Vandermeersch, B., Duday, H., Schepartz, L., \& Rak, Y. (1989). A Middle Palaeolithic Human Hyoid Bone. Nature, 338, 758-760. http://dx.doi.org/10.1038/338758a0

Banting, E. (2003). Australia: The Culture. New York: Crabtree.

Bar, M., \& Neta, M. (2006). Humans Prefer Curved Visual Objects. Psychological Science, 17, 645-648. http://dx.doi.org/10.1111/j.1467-9280.2006.01759.x

BBC (2013). Vietnam Pair Coaxed out of Jungle. Retrieved 16 December 2014. http://www.bbc.co.uk/news/world-asia-23631738

Binns, C. (2006). Case Closed: Apes Got Culture. Retrieved 15 February 2015. http://www.livescience.com/

Bird, C., \& Emery, N. (2009). Rooks Use Stones to Raise the Water Level to Reach a Floating Worm. Current Biology, 19, 1410-1414. http://dx.doi.org/10.1016/j.cub.2009.07.033 
Boffey, D. (2014). Children’s Hyperactivity “Is Not a Real Disease”, Says US Expert. Retrieved 5 October 2014.

Bond, A. B., Kamil, A. C., \& Balda, R. P. (2003). Social Complexity and Transitive Inference in Corvids. Animal Behaviour, 65, 479-487. http://dx.doi.org/10.1006/anbe.2003.2101

Bond, Y. (2013). Fast French for Busy People: A Step-by-Step Program to Learn French in 24 Hours. Bloomington, IN: iUniverse.

Boysen, S. (1999). Q\&A-PBS. Retrieved 26 August 2014.

Brunet, M., Guy, F., Pilbeam, D., Mackaye, H. T., Likius, A. et al. (2002). A New Hominid from the Upper Miocene of Chad, Central Africa. Nature, 418, 145-151. http://dx.doi.org/10.1038/nature00879

Callaway, E. (2008). Did Hyperactivity Evolve as a Survival Aid for Nomads? New Scientist.

Campbell, B. G. (205). Humankind Emerging. Boston: Allyn \& Bacon.

Carmody, R. N., Weintraub, G. S., \& Wrangham, R. W. (2011). Energetic Consequences of Thermal and Nonthermal Food Processing. Proceedings of the National Academy of Sciences of the United States of America, 108, 19199-19203. http://dx.doi.org/10.1073/pnas.1112128108

Carvalho, S., Biro, D., Cunha, E., Hockings, K., Mcgrew, W., Richmond, B., \& Matsuzawa, T. (2012). Chimpanzee Carrying Behaviour and the Origins of Human Bipedality. Current Biology, 22, R180-R181. http://dx.doi.org/10.1016/j.cub.2012.01.052

Choi, C. Q. (2007). Chimps Do Numbers Better than Humans. Retrieved 17 December 2014. http://www.livescience.com/7444-chimps-numbers-humans.html

Crockford, C., Wittig, R., Langergraber, K., Ziegler, T., Zuberbuhler, K., \& Deschner, T. (2013). Urinary Oxytocin and Social Bonding in Related and Unrelated Wild Chimpanzees. Proceedings of the Royal Society B: Biological Sciences, 280, 20122765. http://dx.doi.org/10.1098/rspb.2012.2765

Darwin, C. (1981). The Descent of Man, and Selection in Relation to Sex. Princeton, NJ: Princeton University Press. http://dx.doi.org/10.5962/bhl.title.70891

Dean, C., Leakey, M., Reid, D., Schrenk, F., Schwartz, G., Stringer, C., \& Walker, A. (2001). Growth Processes in Teeth Distinguish Modern Humans from Homo erectus and Earlier Hominins. Nature, 414, 628-631. http://dx.doi.org/10.1038/414628a

Diamond, J. (1998). Guns, Germs, and Steel: The Fates of Human Societies. New York: W.W. Norton \& Company.

Dingemanse, M., Torreira, F., \& Enfield, N. J. (2013). Is “Huh?” a Universal Word? Conversational Infrastructure and the Convergent Evolution of Linguistic Items. PLOS ONE, 8, e78273. http://dx.doi.org/10.1371/journal.pone.0078273

Dudzinski, K., \& Frohoff, T. (2008). Dolphin Mysteries: Unlocking the Secrets of Communication. New Haven, CT: Yale University Press.

Dunsworth, H., Warrener, A., Deacon, T., Ellison, P., \& Pontzer, H. (2012). Metabolic Hypothesis for Human Altriciality. Proceedings of the National Academy of Sciences of the United States of America, 109, 15212-15216. http://dx.doi.org/10.1073/pnas.1205282109

Eisenberg, D., Campbell, B., Gray, P., \& Sorenson, M. (2008). Dopamine Receptor Genetic Polymorphisms and Body Composition in Undernourished Pastoralists: An Exploration of Nutrition Indices among Nomadic and Recently Settled Ariaal Men of Northern Kenya. BMC Evolutionary Biology, 8, 173-173. http://dx.doi.org/10.1186/1471-2148-8-173

Emery, N. J. (2004). The Mentality of Crows: Convergent Evolution of Intelligence in Corvids and Apes. Science, 306, 1903-1907. http://dx.doi.org/10.1126/science.1098410

Everett, D. (1986). Piraha. In D. C. Derbyshire, \& G. K. Pullum (Eds.), The Handbook of Amazonian Languages, Vol I. Mouton de Gruyter.

Everett, D. L. (2009). Pirahã Culture and Grammar: A Response to Some Criticisms. Language, 85, 405-442. http://dx.doi.org/10.1353/lan.0.0104

Fonseca-Azevedo, K., \& Herculano-Houzel, S. (2012). Metabolic Constraint Imposes Tradeoff between Body Size and Number of Brain Neurons in Human Evolution. Proceedings of the National Academy of Sciences of the United States of America, 109, 18571-18576.

Gallup Jr., G. G. (1970). Chimpanzees: Self Recognition. Science, 167, 86-87. http://dx.doi.org/10.1126/science.167.3914.86

Gibbons, A. (2007). Food for Thought. Science, 316, 1558-1560. http://dx.doi.org/10.1126/science.316.5831.1558

Gill, F. B. (2003). Ornithology. New York: W.H. Freeman.

Goodall, J. (1986). The Chimpanzees of Gombe: Patterns of Behavior. Cambridge, MA: Belknap Press of Harvard University Press.

Guenevere, M. \& Kaplan, H. (2007). Longevity amongst Hunter-Gatherers. Population and Development Review, 33, 321365. 
Haggard, P. (2009). The Sources of Human Volition. Science, 324, 731-733. http://dx.doi.org/10.1126/science.1173827

Harcourt, A., Stewart, K., \& Hauser, M. (1993). Functions of Wild Gorilla “Close” Calls. I. Repertoire, Context, and Interspecific Comparison. Behaviour, 124, 89-122. http://dx.doi.org/10.1163/156853993X00524

Hartmann, T. (1995). ADD Success Stories. Grass Valley, CA: Underwood Books.

Hawks, J. (2013). How Has the Human Brain Evolved over the Years? Scientific American Mind, 24, 76.

Hughes, D., \& Hulse, A. (2001). Gorillas among Us: A Primate Ethnographer's Book of Days. Tucson, AZ: University of Arizona Press.

Inoue, S., \& Matsuzawa, T. (2007). Working Memory of Numerals in Chimpanzees. Current Biology, 17, R1004-R1005. http://dx.doi.org/10.1016/j.cub.2007.10.027

Jerison, H. J. (1973). Evolution of the Brain and Intelligence. New York: Academic Press.

Johnson, L. E. (1993). A Morally Deep World: An Essay on Moral Significance and Environmental Ethics (p. 27). Cambridge, England: Cambridge University Press.

Kluger, J. (2010). Inside the Minds of Animals. What Animals Think.

Köhler, W. (1929). Gestalt Psychology. New York: Liveright.

Krubitzer, L., \& Disbrow, E. (2008) The Evolution of Parietal Areas Involved in Hand Use in Primates. In J. Kaas, \& E. Gardner (Eds.), The Senses: A Comprehensive Reference. Volume 6, Somatosensation (pp. 183-214). London: Elsevier.

Laver, J. (1994). Principles of Phonetics. Cambridge: Cambridge University Press. http://dx.doi.org/10.1017/CBO9781139166621

Mathevon, N., Vergne, A., \& Aubin, T. (2013). Acoustic Communication in Crocodiles: How Do Juvenile Calls Code Information? The Journal of the Acoustical Society of America, 133, 3257-3257. http://dx.doi.org/10.1121/1.4805255

Mayes, S. D., Calhoun, S. L., \& Crowell, E. W. (2000). Learning Disabilities and ADHD: Overlapping Spectrum Disorders. Journal of Learning Disabilities, 33, 417-424. http://dx.doi.org/10.1177/002221940003300502

McComb, K., Baker, L., \& Moss, C. (2006). African Elephants Show High Levels of Interest in the Skulls and Ivory of Their Own Species. Biology Letters, 2, 26-28. http://dx.doi.org/10.1098/rsbl.2005.0400

McCroskey, J. C., Wrench, J. S., \& Richmond, V. P. (2003). Principles of Public Speaking. Indianapolis, IN: The College Nework.

McHenry, H. M. (2009). Human Evolution. In M. Ruse, \& J. Travis (Eds.), Evolution: The First Four Billion Years (p. 263). Cambridge, MA: The Belknap Press of Harvard University Press.

Miller, E. K., Freedman, D. J., \& Wallis, J. D. (2002). The Prefrontal Cortex: Categories, Concepts and Cognition. Philosophical Transactions of the Royal Society of London. Series B, Biological Sciences, 357, 1123-1136. http://dx.doi.org/10.1098/rstb.2002.1099

Miller, G. (2005). What Is the Biological Basis of Consciousness? Science, 309, 79-79. http://dx.doi.org/10.1126/science.309.5731.79

Mithen, S. (2006). Ethnobiology and the Evolution of the Human Mind. Journal of the Royal Anthropological Institute, 12, S45-S61. http://dx.doi.org/10.1111/j.1467-9655.2006.00272.x

Munck, O., \& Lassen, N. (1957). Bilateral Cerebral Blood Flow and Oxygen Consumption in Man by Use of Krypton ${ }^{85}$. Circulation Research, 5, 163-168. http://dx.doi.org/10.1161/01.RES.5.2.163

Nelson, C. A. (2000). The Neurobiological Bases of Early Intervention. In J. P. Shonkoff, \& S. J. Meisels (Eds.), Handbook of Early Childhood Intervention (2nd ed., pp. 204-228). Cambridge, MA: Cambridge University Press. http://dx.doi.org/10.1017/CBO9780511529320.012

Nestler, E. J., Hyman, S. E., \& Malenka, R. C. (2009). Molecular Neuropharmacology: A Foundation for Clinical Neuroscience. New York: McGraw-Hill, Medical Pub. Div.

Nosowitz, D. (2013). This Cat Did Not Figure Out How Mirrors Work. http://www.popsci.com/science/article/2013-04/cat-did-not-figure-out-how-mirrors-work

O’neill, T. (2013). Why All Babies Say “Mama”. https://www.salon.com/2013/05/13/why_all_babies_say_mama_partner/

Pagel, M. (2009). “Oldest English Words” Identified. http://news.bbc.co.uk/2/hi/science/nature/7911645.stm

Peters, R. (2006). Ageing and the Brain. Postgraduate Medical Journal, 82, 84-88.

Pika, S., \& Bugnyar, T. (2011). The Use of Referential Gestures in Ravens (Corvus corax) in the Wild. Nature Communications, 2, 560. http://dx.doi.org/10.1038/ncomms1567

Poole, J. (1996). Coming of Age with Elephants: A Memoir. New York: Hyperion. 
Prior, H., Schwarz, A., Güntürkün, O., \& Waal, F. (2008). Mirror-Induced Behavior in the Magpie (Pica pica): Evidence of Self-Recognition. PLoS Biology, 6, E202. http://dx.doi.org/10.1371/journal.pbio.0060202

Proctor, D., Williamson, R., Waal, F., \& Brosnan, S. (2013). Chimpanzees Play the Ultimatum Game. Proceedings of the National Academy of Sciences of the United States of America, 110, 2070-2075.

Raffaele, P. (2014). History, Travel, Arts, Science, People, Places. Smithsonian. http://www.smithsonianmag.com/science-nature/speaking-bonobo-134931541/

Sackett, R. (1996). Time, Energy, and the Indolent Savage: A Quantitative Cross-Cultural Test of the Primitive Affluence Hypothesis. Ph.D. Dissertation, Los Angeles, CA: University of California.

Sahlins, M. (1968). Notes on the Original Affluent Society. In R. B. Lee, \& I. DeVore (Eds.), Man the Hunter. New York: Aldine Publishing Company.

Schaik, C. (2006). Why Are Some Animals So Smart? Scientific American, 294, 64-71. http://dx.doi.org/10.1038/scientificamerican0406-64

Scholz, M., D’Août, K., Bobbert, M., \& Aerts, P. (2006). Vertical Jumping Performance of Bonobo (Pan paniscus) Suggests Superior Muscle Properties. Proceedings of the Royal Society B: Biological Sciences, 273, 2177-2184. http://dx.doi.org/10.1098/rspb.2006.3568

Schwartz, J. H. (1988). Orang-Utan Biology. New York: Oxford University Press.

Scott, M. (2013). Corollary Discharge Provides the Sensory Content of Inner Speech. Psychological Science, 24, $1824-1830$. http://dx.doi.org/10.1177/0956797613478614

Shattuck, R. (1980). The Forbidden Experiment. New York: Farrar Straus Giroux.

Smith, K. (2007). Cognitive Psychology: Mind and Brain (pp. 21, 194-199, 349). Upper Saddle River, NJ: Prentice Hall.

Smith, L. G. (1984). Lives in Education: People and Ideas in the Development of Teaching. Ames, IA: Educational Studies Press.

Sockol, M., Raichlen, D., \& Pontzer, H. (2007). Chimpanzee Locomotor Energetics and the Origin of Human Bipedalism. Proceedings of the National Academy of Sciences of the United States of America, 104, 12265-12269. http://dx.doi.org/10.1073/pnas.0703267104

Suwa, G., Kono, R. T., Simpson, S. W., Asfaw, B., Lovejoy, C. O., \& White, T. D. (2009). Paleobiological Implications of the Ardipithecus ramidus Dentition. Science, 326, 94-99.

Videan, E., \& McGrew, W. (2002). Bipedality in Chimpanzee (Pan troglodytes) and Bonobo (Pan paniscus): Testing Hypotheses on the Evolution of Bipedalism. American Journal of Physical Anthropology, 118, 184-190.

Wada, J., \& Rasmussen, T. (1960). Intracarotid Injection of Sodium Amytal for the Lateralization of Cerebral Speech Dominance. Experimental and Clinical Observations. Journal of Neurosurgery, 17, 266-282. http://dx.doi.org/10.3171/jns.1960.17.2.0266

Walker, A. (2009). The Strength of Great Apes and the Speed of Humans. Current Anthropology, 50, 229-234. http://dx.doi.org/10.1086/592023

Wildman, D. E. (2003). Implications of Natural Selection in Shaping 99.4\% Nonsynonymous DNA Identity between Humans and Chimpanzees: Enlarging Genus Homo. Proceedings of the National Academy of Sciences of the United States of America, 100, 7181-7188. http://dx.doi.org/10.1073/pnas.1232172100

Wise, S. M. (2002). Drawing the Line (pp. 93-108). Cambridge, MA: Perseus Books.

Wolchover, B. (2011). Chimps vs. Humans: How Are We Different? Retrieved 16 January 2015. http://www.livescience.com/15297-chimps-humans.html

Wong, K. (2012). Helpless by Design? Scientific American, 307, 28.

Wrangham, R. (2009). Catching Fire: How Cooking Made Us Human. New York: Basic Books.

Wrangham, R., \& Carmody, R. (2010). Human Adaptation to the Control of Fire. Evolutionary Anthropology: Issues, News, and Reviews, 19, 187-199. http://dx.doi.org/10.1002/evan.20275 